\title{
Respostas fisiológicas e de desempenho de leitões suplementados com B-glucanos e desafiados imunologicamente
}

\author{
[Phisiologial responses and growth performance of immune challenged piglets \\ supplemented with B-glucans] \\ V.S. Ledur ${ }^{1}$, A.M.L. Ribeiro ${ }^{2}$, A.M. Kessler ${ }^{2}$, M.F. Gianfelici ${ }^{1}$, M.M. Vieira ${ }^{1}$, \\ J. Grandi ${ }^{3}$, T.G. Machinsky ${ }^{1}$

\footnotetext{
${ }^{1}$ Aluno de pós-graduação - Universidade Federal do Rio Grande do Sul - Porto Alegre, RS

${ }^{2}$ Departamento de Zootecnia - Universidade Federal do Rio Grande do Sul - Porto Alegre, RS

${ }^{3}$ Aluno de graduação - Universidade Federal do Rio Grande do Sul - Porto Alegre, RS
}

\begin{abstract}
RESUMO
O estudo buscou avaliar as respostas fisiológicas e de desempenho à adição de diferentes níveis de $\beta$ glucanos na dieta de leitões recém-desmamados. Foram utilizados 30 machos de linhagem comercial, com 34 dias de idade e peso de 10,9 $\pm 0,63 \mathrm{~kg}$, alojados em gaiolas individuais, durante 14 dias. Os tratamentos variaram somente nos níveis de $\beta$-glucanos que foram de 35, 70,140 e $280 \mathrm{~g} / \mathrm{T}$. No final desse período, em metade dos animais foram injetados $2,7 \mathrm{mg}$ de lipopolissacarídeo (LPS) em $1 \mathrm{~mL}$ de solução (PBS)/leitão, e nos demais $1 \mathrm{~mL} /$ leitão de PBS. Foram avaliadas temperatura retal (TR), frequência respiratória (FR), perfil bioquímico sanguíneo e sinais clínicos aos 30, 90, 120 e 390 minutos seguintes à injeção. As respostas de desempenho não foram afetadas pelos níveis de $\beta$-glucanos. Foi observado o aumento de TR, tanto em função do LPS como em função da hora em que a temperatura foi medida. No entanto, os animais LPS-injetados, que receberam $280 \mathrm{~g} / \mathrm{T}$ de $\beta$-glucanos, tiveram a mesma TR daqueles LPS-não injetados. Os sinais clínicos foram compatíveis com um quadro de inflamação aguda e foram observados, nos animais LPS-injetados, vômito, prostração e diarreia, sendo que a inclusão de $\beta$-glucanos não conseguiu reverter esses sintomas. $\mathrm{O}$ uso de $\beta$-glucanos por 14 dias na dieta de leitões recémdesmamados mostrou um efeito anti-inflamatório em situação de desafio agudo. Para reverter o desafio imunológico utilizado, o nível de $280 \mathrm{~g} / \mathrm{T}$ de $\beta$-glucanos mostrou-se o mais recomendado.
\end{abstract}

Palavras-chave: desempenho, imunologia, lipopolissacarídeo, leitões, $\beta$-glucanos

\begin{abstract}
This study was done to evaluate immunological responses and performance of weaning piglets receiving diets with different levels of $\beta$-glucans. Thirty males from a commercial line with 34 days of age and $10.9 \pm 0,6 \mathrm{~kg}$ initial weight were housed in individual metabolic cages during 14 days. The treatments only differed in $\beta$-glucans levels: $35 ; 70 ; 140$ and $280 \mathrm{~g} / T$. On the $14^{\text {th }}$ day, half of the pigs were inoculated with $2.7 \mathrm{mg}$ LPS (lipopolysaccharide)/mL of solution (PBS)/pig and the other half received $1 \mathrm{~mL}$ PBS/pig. Rectal temperature (RT), respiratory frequency $(R F)$, biochemical profile and animal behavior (120 and 390 minutes after LPS inoculation) were evaluated. As the experiment was conducted, performance was not affected by $\beta$-glucans. An RT increase was observed due to LPS and time of temperature measurement. LPS-injected animals receiving $280 \mathrm{~g} / T$ of $\beta$-glucans had the same RT as the LPS- non injected group. Clinical signs were near the expectation for acute inflammation. LPS-injected presented prostration, diarrhea and vomit and the $\beta$-glucans did not reverse this situation. The use of $\beta$-glucans in weaning pigs for fourteen days showed an anti-inflammatory action. To revert the immunologic challenge, the level of $280 \mathrm{~g} / \mathrm{T}$ of $\beta$-glucans was the most recommended.
\end{abstract}

Keywords: performance, immunology, lipopolysaccharides, pigs, $\beta$-glucans

Recebido em 19 de agosto de 2010

Aceito em 28 de setembro de 2011

E-mail: vsledur@hotmail.com 


\section{INTRODUÇÃO}

Em 2011 a suinocultura brasileira aumentou a exportação de carne, ampliando as vendas para Hong Kong e Argentina, segundo e terceiro mercados importadores, respectivamente, além da reabertura do mercado sul africano e de expectativas de venda no mercado japonês (Exportações, 2011). Dentro desse contexto de desenvolvimento e crescimento comercial, a nutrição possui grande destaque para aumentar a competitividade do produto, já que recentemente têm surgido descobertas de novos ingredientes associados a melhorias no sistema imune dos animais em substituição aos promotores de crescimento.

Os $\beta$-glucanos são polímeros de glicose constituintes da parede celular dos organismos e da fibra alimentar solúvel. Esses polissacarídeos (ß 1,3 e $\beta 1,6)$ atuam como imunoestimulantes ao interagirem com as células de defesa, tais como macrófagos e linfócitos que, uma vez estimulados, aumentam a secreção de substâncias antimicrobianas, potencializando a destruição de microorganismos patogênicos (Seljelid et al., 1987).

As pesquisas em relação à participação dos $\beta$ glucanos na resposta imune de leitões na fase de creche realizadas por Schoenherr et al. (1994) sugerem que ocorre uma melhora no desempenho e na conversão alimentar. Já Cheng et al. (2004), trabalhando com frangos, e Hanh et al. (2006), com leitões, não verificaram melhoras significativas. Em peixes, a estimulação da resposta imune promovida pelos $\beta$-glucanos já foi comprovada (Robertsen et al., 1990) e, em humanos, a atividade imunobiológica destas moléculas também é reconhecida, mas seu mecanismo de participação no processo imune ainda não está elucidado (Amati et al., 2005).

O objetivo do presente trabalho foi avaliar temperatura retal, frequência respiratória, perfil bioquímico sanguíneo entre outras respostas fisiológicas, de leitões recém-desmamados, desafiados imunologicamente por LPS, frente à adição de diferentes níveis de $\beta$-glucanos na dieta.

\section{MATERIAL E MÉTODOS}

O experimento foi realizado no Laboratório de Ensino Zootécnico - LEZO - da Universidade Federal do Rio Grande do Sul. Os leitões recémdesmamados foram alojados em sala climatizada composta por 30 gaiolas metabólicas individuais, equipadas com dois cochos e um bebedouro tipo chupeta e piso ripado. Foram utilizados 30 machos de mesma linhagem comercial, com 34 dias de idade e peso inicial de aproximadamente $10,9 \pm 0,63 \mathrm{~kg}$. O período experimental teve duração de 14 dias.

As dietas experimentais foram formuladas de acordo com as Tabelas Brasileiras para Aves e Suínos (Rostagno, 2005), a partir de uma única dieta basal isoproteica e isoenergética, que foi oferecida à vontade, assim como a água. Os tratamentos variaram somente no nível de $\beta$ glucanos (inclusão como produto comercial) em substituição ao amido de milho, sendo que os níveis finais de $\beta$-glucanos foram 35, 70, 140, $280 \mathrm{~g} / \mathrm{T}$.

Diariamente foi observada a ocorrência de diarreia, no entanto os animais apresentaram boa saúde do início ao fim do período experimental. No último dia deste período, estando os leitões com 48 dias de idade e $18 \mathrm{~kg}$ de peso vivo em média, foi realizado um ensaio imunológico com os 30 animais. Injetou-se $1 \mathrm{~mL}$ de solução contendo lipopolissacarídeo (LPS) de Escherichia coli, sorotipo 055: B5 com mais de 500.000 UE (unidade de endotoxina)/mg (SigmaAldrich, 2009) na dosagem de $150 \mu \mathrm{g}$ de LPS $/ \mathrm{kg}$ de peso vivo em três leitões por tratamento, via intramuscular. Cada $1 \mathrm{~mL}$ de solução teve concentração de $2,7 \mathrm{mg}$ de LPS. Nos demais leitões de cada tratamento, foi injetado PBS (solução tampão) na dose de $1 \mathrm{~mL} /$ leitão.

Além das respostas de desempenho - consumo de ração (CR), ganho de peso (GP) e conversão alimentar (CA) -, foram avaliadas: temperatura retal (TR) medida com termômetros digitais no tempo zero e aos $15,30,45,60,90,120,150$, 180 minutos após inoculação; frequência respiratória aos 60 minutos após inoculação e escores de sinais clínicos aos 30, 90, 120 e 390 minutos após inoculação do LPS. Nestes sinais observaram-se a presença ou não de diarreia, vômito e o estado geral (de pé, prostrado, decúbito e decúbito de olhos fechados). 
Tabela 1. Composição de ingredientes e níveis nutricionais calculados das rações experimentais para a fase inicial

\begin{tabular}{|c|c|c|c|c|c|}
\hline \multirow{2}{*}{ Ingredientes $\%$} & \multicolumn{5}{|c|}{ Tratamentos (g/T. de $\beta$-glucanos) } \\
\hline & 0 & 35 & 70 & 140 & 280 \\
\hline Milho & 53,30 & 53,30 & 53,30 & 53,30 & 53,30 \\
\hline Farelo de soja & 26,73 & 26,73 & 26,73 & 26,73 & 26,73 \\
\hline$\beta$ - glucanos $(\mathrm{g} / \mathrm{T})$ & 0 & 35 & 70 & 140 & 280 \\
\hline Amido de milho & 0,04 & 0,035 & 0,03 & 0,02 & 0 \\
\hline Glúten de milho & 4,0 & 4,0 & 4,0 & 4,0 & 4,0 \\
\hline Açúcar & 3,0 & 3,0 & 3,0 & 3,0 & 3,0 \\
\hline Soro de leite & 5,73 & 5,73 & 5,73 & 5,73 & 5,73 \\
\hline Óleo de soja degomado & 3,0 & 3,0 & 3,0 & 3,0 & 3,0 \\
\hline Fosfato bicálcico & 1,67 & 1,67 & 1,67 & 1,67 & 1,67 \\
\hline Calcário & 0,58 & 0,58 & 0,58 & 0,58 & 0,58 \\
\hline Lisina & 0,54 & 0,54 & 0,54 & 0,54 & 0,54 \\
\hline DL - Metionina & 0,20 & 0,20 & 0,20 & 0,20 & 0,20 \\
\hline $\mathrm{L}$ - Treonina & 0,20 & 0,20 & 0,20 & 0,20 & 0,20 \\
\hline Colina & 0,07 & 0,07 & 0,07 & 0,07 & 0,07 \\
\hline Sal comum & 0,45 & 0,45 & 0,45 & 0,45 & 0,45 \\
\hline Acidificante & 0,30 & 0,30 & 0,30 & 0,30 & 0,30 \\
\hline Antioxidante & 0,015 & 0,015 & 0,015 & 0,015 & 0,015 \\
\hline Premix mineral & 0,12 & 0,12 & 0,12 & 0,12 & 0,12 \\
\hline Premix vitaminas & 0,05 & 0,05 & 0,05 & 0,05 & 0,05 \\
\hline \multicolumn{6}{|l|}{ Nutrientes calculados } \\
\hline Proteína bruta \% & 20,0 & 20,0 & 20,0 & 20,0 & 20,0 \\
\hline Energia metab. (kcal/kg) & 3400 & 3400 & 3400 & 3400 & 3400 \\
\hline Gordura total \% & 5,40 & 5,40 & 5,40 & 5,40 & 5,40 \\
\hline Lactose $\%$ & 4,0 & 4,0 & 4,0 & 4,0 & 4,0 \\
\hline $\mathrm{Ca} \%$ & 0,73 & 0,73 & 0,73 & 0,73 & 0,73 \\
\hline P disponível \% & 0,45 & 0,45 & 0,45 & 0,45 & 0,45 \\
\hline Sódio \% & 0,25 & 0,25 & 0,25 & 0,25 & 0,25 \\
\hline Lisina total $\%$ & 1,40 & 1,40 & 1,40 & 1,40 & 1,40 \\
\hline Metionina \% & 0,54 & 0,54 & 0,54 & 0,54 & 0,54 \\
\hline Met. + Cis \% & 0,85 & 0,85 & 0,85 & 0,85 & 0,85 \\
\hline Triptofano $\%$ & 0,25 & 0,25 & 0,25 & 0,25 & 0,25 \\
\hline Treonina $\%$ & 0,94 & 1,02 & 1,02 & 1,02 & 1,02 \\
\hline
\end{tabular}

Aos 180 minutos pós-inoculação, também foram avaliados os seguintes parâmetros bioquímicos sanguíneos: albuminas séricas; globulinas séricas; alanina amino transferase-AST; aspartato amino transferase-ALT; fosfatase alcalina-FAL; proteína $\mathrm{C}$ reativa. Esta última constitui uma proteína de fase aguda que, sendo sintetizada pelo fígado, em tese permite detectar uma resposta inflamatória.

Utilizou-se um delineamento completamente casualizado, com cinco níveis de $\beta$-glucanos e seis repetições, totalizando 30 unidades experimentais. As análises estatísticas foram realizadas pelo programa computacional Statistical... (2001). Os resultados de desempenho, frequência respiratória, proteínas totais, albumina, globulina e medidas de enzimas no soro sanguíneo foram submetidos à análise de variância pelo método dos quadrados mínimos generalizados (GLM), considerando-se LPS (injetado, não injetado) como fator qualitativo. Para as respostas de desempenho, também foi realizada análise de regressão simples em função dos níveis de $\beta$-glucanos. A resposta de temperatura retal foi testada por análise de variância, considerando-se como fatores nível de $\beta$-glucanos, minutos e LPS, e também por regressão múltipla, em função dos níveis de $\beta$ glucanos por LPS. As respostas qualitativas (proteína $\mathrm{C}$ reativa no soro sanguíneo e escores de sinais clínicos) foram analisadas por quiquadrado. As médias foram testadas pelo teste Student-Newman-Keuls, em significância de 5\%.

\section{RESULTADOS E DISCUSSÃO}

Na análise de variância (GLM), os níveis de $\beta$ glucanos não influenciaram as respostas de desempenho $(\mathrm{P}>0,05)$, como pode ser observado 
na Tab. 2. Na análise de regressão, o ganho de peso dos animais teve comportamento quadrático $(\mathrm{P}<0,09)$, enquanto a conversão alimentar teve comportamento cúbico, ambas as respostas sem aplicabilidade prática. No presente estudo, os 14 dias de dieta com $\beta$-glucanos foram insuficientes para avaliação consistente de desempenho. Dritz et al. (1995), trabalhando com leitões no período de sete a 35 dias pós desmame e oferecendo dois níveis de dieta ( 0 e $1 \%$ de $\beta$-glucanos), também não observaram diferenças significativas nas medidas de desempenho. Por outro lado, Eicher et al. (2006) suplementando $2,5 \%$ de $\beta$-glucanos na dieta por quatro semanas em leitões desde o primeiro dia de vida, observaram um maior ganho de peso nesse grupo, comparado aos animais sem o suplemento. Também Mendes et al. (2010),com leitões dos 21 aos 60 dias de idade, observaram maior ganho de peso para aqueles suplementados com 240g/T de $\beta$ glucanos em relação ao grupo-controle. Os autores somente observaram esse efeito no período total, pois de 21 a 35 ou a 49 dias de idade não houve efeito positivo, indicando que o uso do produto deva ser feito por um período mais prolongado.

Tabela 2. Efeito de níveis crescentes de $\beta$-glucanos sobre o desempenho de leitões de 14 a 28 dias pósdesmame

\begin{tabular}{cccc}
\hline$\beta$ - glucanos $(\mathrm{g} / \mathrm{T})$ & CR $(\mathrm{kg})$ & $\mathrm{GP}(\mathrm{kg})$ & $\mathrm{CA}$ \\
\hline 0 & 11,58 & 7,83 & 1,484 \\
35 & 11,99 & 8,30 & 1,445 \\
70 & 10,34 & 7,18 & 1,447 \\
140 & 10,91 & 6,84 & 1,605 \\
280 & 10,33 & 7,53 & 1,458 \\
Probabilidade & 0,281 & 0,145 & 0,067 \\
CV \% & 9,27 & 10,5 & 5,31 \\
Análise de Regressão & $\mathrm{NS}$ & Quadrática & Cúbica \\
Probabilidade & & $\mathrm{P}<0,09^{1}$ & $\mathrm{P}<0,03^{2}$ \\
\hline${ }^{1} \mathrm{GP}=8,162-10,12 * \mathrm{X}+10,183^{2} \mathrm{X}^{2} ; \mathrm{X}=\beta$-glucanos $(\mathrm{g} / \mathrm{T})$ & &
\end{tabular}

${ }^{2} \mathrm{CA}=1,487-1,978 * \mathrm{X}+20,81 * \mathrm{X}^{2}-40,12 * \mathrm{X}^{3} ; \mathrm{X}=\beta$-glucanos $(\mathrm{g} / \mathrm{T})$

Da análise de temperatura retal ao longo do tempo (minutos), em função da inoculação de LPS e níveis de $\beta$-glucanos, apenas serão mostradas as interações significativas. A Fig. 1 descreve a interação observada entre minutos e LPS $(\mathrm{P}<0,0001)$ para a resposta temperatura retal. Foi observado o aumento desta após a inoculação tanto de LPS quanto de PBS, ao longo do período. Leitões que receberam LPS tiveram maior TR ao longo do período medido do que aqueles em que foi injetado PBS. O estudo realizado por Wright et al. (2000) mostrou que leitões de aproximadamente 35 dias de idade, inoculados com LPS, também tiveram aumento significativo da TR, além de uma elevação significativa nos níveis de cortisol plasmático, duas horas pós injeção.

O LPS é um dos padrões moleculares expressos sobre a superfície dos patógenos que pode desencadear uma resposta das células fagocíticas do organismo quando injetado (Roitt e Delves, 2004), resultando na fase aguda de resposta. Isto acontece porque um animal, quando desafiado imunologicamente, produz diversas citoquinas que podem aumentar a taxa metabólica, diminuir o apetite e, até mesmo, redirecionar os nutrientes para atender às necessidades energéticas da resposta imune, em vez de crescimento muscular. Esta etapa, chamada de fase aguda de resposta, caracteriza-se por aumento na síntese de proteínas específicas, aumento do turnover proteico, da gliconeogênese e da temperatura corporal (Klasing e Leshchinsky, 1999). Desta forma, o aumento da temperatura retal é um claro indicativo de que os animais estavam sofrendo a fase de resposta inflamatória. Por outro lado, observa-se um aumento de temperatura no grupo-controle. Esta resposta pode ser atribuída ao fato de os animais estarem sendo constantemente manejados, consequentemente sendo estressados. 
Temperatura

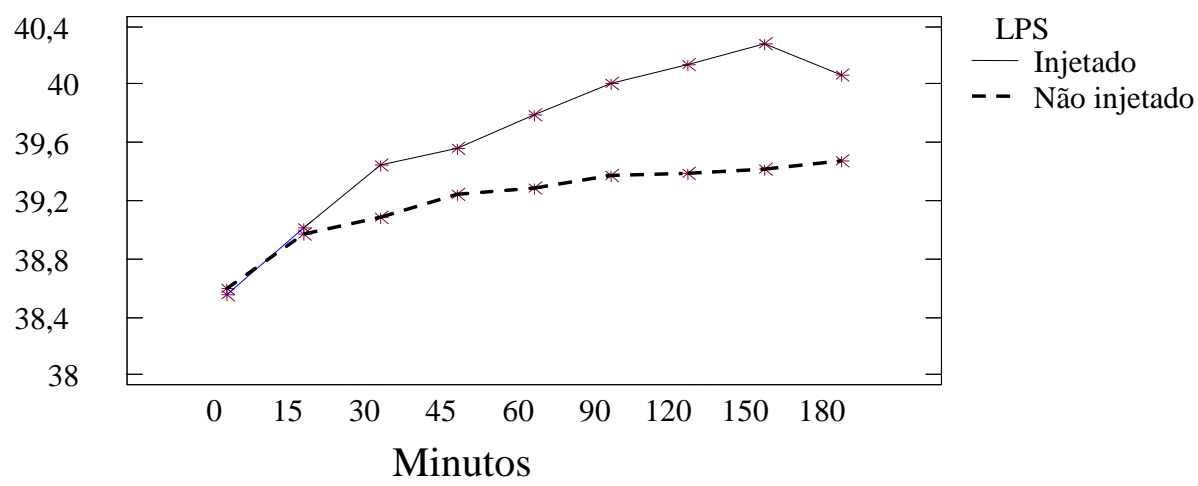

Figura 1. Temperatura retal $\left({ }^{\circ} \mathrm{C}\right)$ ao longo do tempo (0 a 180 minutos) em função da inoculação (s) ou não (n) de LPS

A resposta de temperatura retal também mostrou uma interação significativa $(\mathrm{P}<0,005)$ entre LPS e nível de $\beta$-glucanos (Fig. 2). A figura mostra que os leitões LPS-injetados, que estavam recebendo $280 \mathrm{~g} / \mathrm{T}$ de $\beta$-glucanos na dieta, tiveram a mesma temperatura retal daqueles LPS-não injetados. Este resultado é um forte indicador de que os $\beta$-glucanos têm uma ação anti-inflamatória. Li et al. (2005), ao utilizarem níveis de 0 e $50 \mathrm{mg} / \mathrm{kg}$ de $\beta$-glucanos adicionados na dieta, observaram que leitões consumindo $\beta$ glucanos tiveram um aumento na produção de IL-10 e uma atenuação na elevação de IL-6 e TNF. Para Zhong et al. (2008), a melhor relação entre desempenho e resposta imune de leitões foi obtida na suplementação de $50 \mathrm{mg} / \mathrm{kg}$ de $\beta$ glucanos. No caso do presente trabalho, a ação anti-inflamatória iniciou-se com a dose de $70 \mathrm{~g} / \mathrm{T}$, mas foi mais acentuada na dose mais elevada. Estes resultados também concordam com os de Mao et al. (2005), que verificaram uma participação efetiva dos $\beta$-glucanos na resposta imunológica de leitões frente a injeções de LPS, aumentando a proliferação linfocitária e diminuindo a liberação de citoquinas e corticosteroides quando foram adicionados $500 \mathrm{mg} / \mathrm{kg}$ na dieta. Por outro lado, Mendes et al. (2010), buscando maior produção de anticorpos contra Micoplasma hyopneumoniae, não obtiveram diferenças significativas para esta resposta entre leitões suplementados com 60, 120,180 ou $240 \mathrm{~g} / \mathrm{T}$ de $\beta$-glucanos.

$\mathrm{Na}$ análise de regressão múltipla $(\mathrm{P}<0,01$ $\mathrm{R}^{2}=0,13$ ), para a resposta de temperatura retal, foi verificado que os grupos LPS responderam diferentemente, em função da inclusão de $\beta$ glucanos na dieta (Fig. 3). Nos LPS-injetados, a temperatura retal diminuiu em função da inclusão (Temperatura $=39,79-0,0014^{*} \beta$ glucanos), enquanto nos LPS- não injetados, a temperatura retal aumentou (Temperatura = $39,11+0,0008^{*} \beta$-glucanos), embora com menor inclinação. Com essa análise, evidencia-se o efeito anti-inflamatório do uso de $\beta$-glucano na dieta dos animais desafiados (LPS injetados), evitando a elevação da temperatura corporal. 


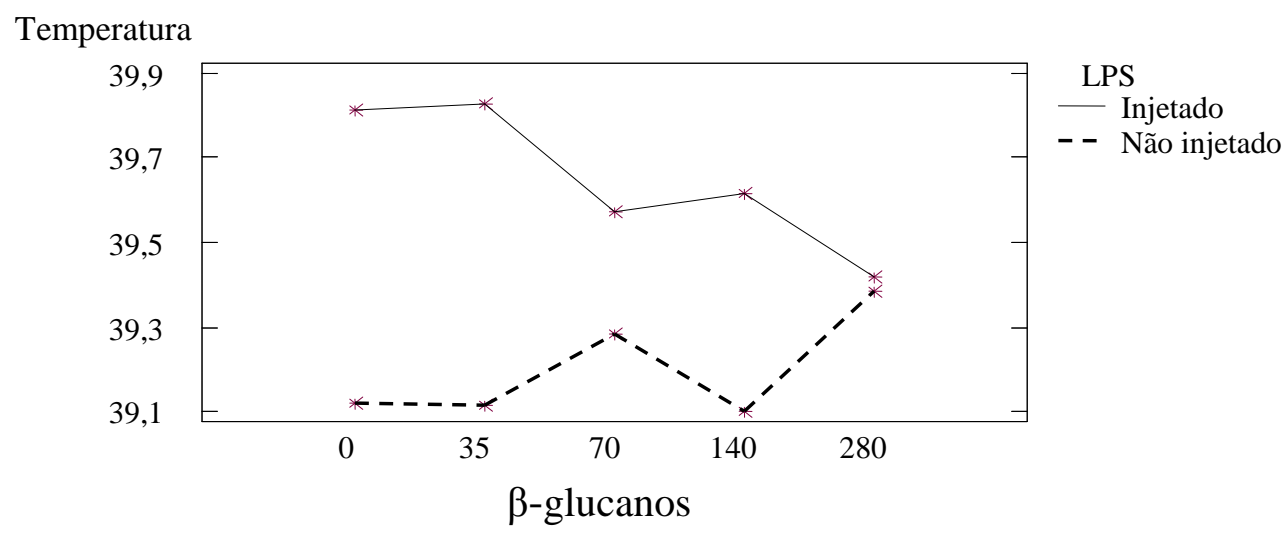

Figura 2. Temperatura retal $\left({ }^{\circ} \mathrm{C}\right)$ conforme inclusão de $\beta$-glucanos na dieta em função da inoculação ou não de LPS

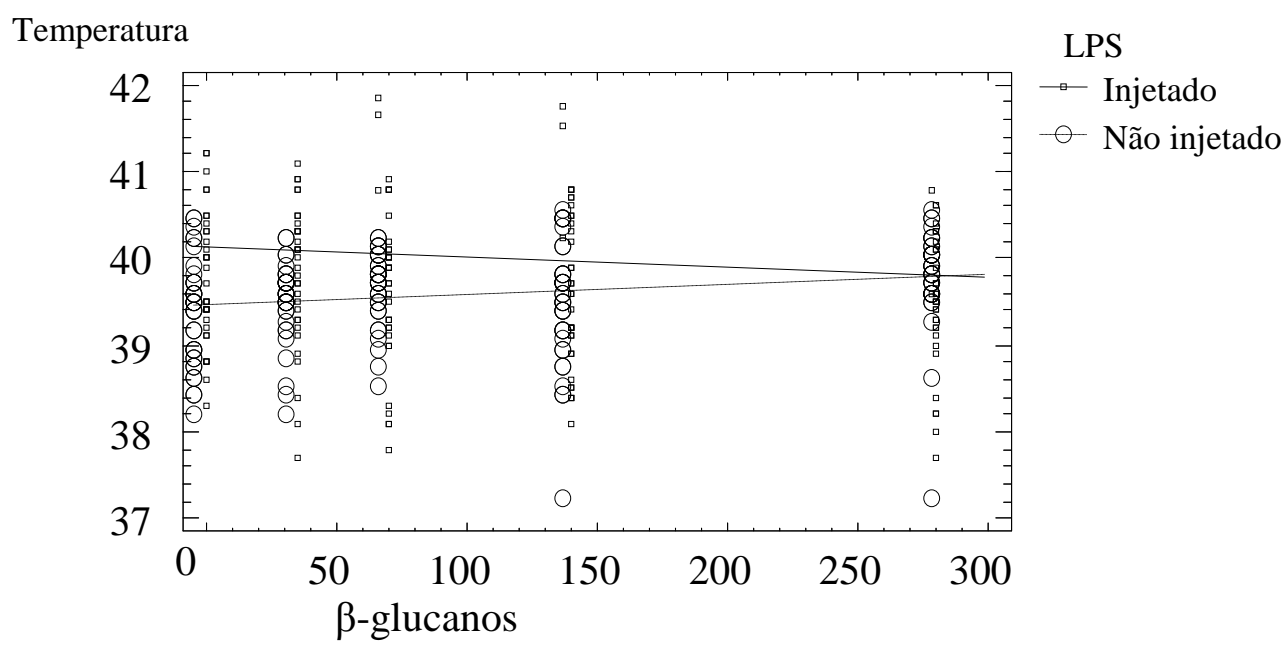

Figura 3. Regressão múltipla entre temperatura retal e LPS em função dos níveis de $\beta$-glucanos da dieta.

$\mathrm{Na}$ Tab. 3, encontram-se as respostas de frequência respiratória. Comparando-se os grupos LPS injetados e LPS- não injetados, observa-se que a frequência dos LPS injetados foi significativamente maior do que dos LPS não injetados. Em relação aos $\beta$-glucanos, a frequência respiratória não diferiu significativamente, independentemente do nível usado na dieta.

As respostas sanguíneas mostraram que a injeção de LPS fez as proteínas totais diminuírem de forma significativa, independentemente do nível de $\beta$-glucanos (Tab. 4). Queda nas proteínas totais é uma resposta esperada em casos de reação inflamatória aguda (Silva et al., 2005). As albuminas séricas (Tab. 3) também diminuíram significativamente no grupo LPS injetado. Para globulinas, não houve uma resposta clara, nem para LPS, nem para o papel dos $\beta$-glucanos. Do mesmo modo, a proteína $\mathrm{C}$ reativa, que era esperada aumentar em função de ser produzida no fígado em situações de estresse (Silva et al., 2005), como ocorreu neste experimento, não mostrou resultados significativos. 
Tabela 3. Análise de frequência respiratória/minuto - 60 minutos após inoculação LPS

\begin{tabular}{|c|c|c|}
\hline \multirow{2}{*}{$\beta$-glucanos (g/T) } & \multicolumn{2}{|c|}{ LPS } \\
\hline & Não injetado & Injetado \\
\hline 0 & 57 & 117 \\
\hline 35 & 62 & 96 \\
\hline 70 & 59 & 67 \\
\hline 140 & 55 & 60 \\
\hline 280 & 39 & 85 \\
\hline Média & $54 \mathrm{~b}$ & $85 \mathrm{a}$ \\
\hline \multicolumn{3}{|l|}{ Probabilidade } \\
\hline B-glucanos & \multicolumn{2}{|c|}{0,398} \\
\hline LPS & \multicolumn{2}{|c|}{0,012} \\
\hline$\beta$-glucanos *LPS & \multicolumn{2}{|c|}{0,474} \\
\hline $\mathrm{CV} \%$ & \multicolumn{2}{|c|}{43,8} \\
\hline
\end{tabular}

Tabela 4. Análise das proteínas totais, albumina e globulina no soro sanguíneo em g/L - 180 minutos após inoculação LPS

\begin{tabular}{|c|c|c|c|c|c|c|}
\hline \multirow{3}{*}{$\begin{array}{c}\beta-\text { glucanos } \\
(\mathrm{g} / \mathrm{T})\end{array}$} & \multicolumn{2}{|c|}{ Proteínas totais } & \multicolumn{2}{|c|}{ Albumina } & \multicolumn{2}{|c|}{ Globulina } \\
\hline & \multicolumn{6}{|c|}{ LPS } \\
\hline & $\begin{array}{c}\text { Não } \\
\text { injetado }\end{array}$ & Injetado & $\begin{array}{c}\text { Não } \\
\text { injetado }\end{array}$ & Injetado & $\begin{array}{c}\text { Não } \\
\text { injetado }\end{array}$ & Injetado \\
\hline 0 & 53,3 & 49,0 & 26,3 & 24,7 & 27,0 & 24,3 \\
\hline 35 & 54,7 & 42,7 & 27,3 & 23,0 & 27,3 & 19,7 \\
\hline 70 & 55,0 & 52,0 & 25,7 & 26,0 & 29,3 & 26,0 \\
\hline 140 & 58,0 & 50,0 & 27,7 & 24,7 & 30,3 & 25,3 \\
\hline 280 & 53,3 & 53,3 & 25,0 & 21,3 & 28,3 & 31,7 \\
\hline Média & $54,9^{\mathrm{a}}$ & $49,4 \mathrm{~b}$ & $26,4 \mathrm{a}$ & $23,9 b$ & 28,45 & 25,4 \\
\hline \multicolumn{7}{|l|}{ Probabilidade } \\
\hline$\beta$-glucanos & \multicolumn{2}{|c|}{0,274} & \multicolumn{2}{|c|}{0,060} & \multicolumn{2}{|c|}{0,291} \\
\hline LPS & \multicolumn{2}{|c|}{0,004} & \multicolumn{2}{|c|}{0,001} & \multicolumn{2}{|c|}{0,123} \\
\hline B-gluc. *LPS & \multicolumn{2}{|c|}{0,236} & \multicolumn{2}{|c|}{0,142} & \multicolumn{2}{|c|}{0,476} \\
\hline $\mathrm{CV} \%$ & \multicolumn{2}{|c|}{8,9} & \multicolumn{2}{|c|}{6,5} & \multicolumn{2}{|c|}{19,4} \\
\hline
\end{tabular}

*Médias seguidas de letras minúsculas diferentes na mesma linha diferem em nível de 5\%

Tabela 5. Frequência (\%) da medida de proteína C reativa no soro sanguíneo em mg/dL- 180 minutos após inoculação LPS

\begin{tabular}{cccc}
\hline$\beta-$ glucanos $(\mathrm{g} / \mathrm{T})$ & 6 & 12 & 18 \\
\hline 0 & 50 & 16,7 & 33,3 \\
35 & 66,6 & 16,7 & 16,7 \\
70 & 33,3 & 50 & 16,7 \\
140 & 50 & 33,3 & 16,7 \\
280 & 60 & 40 & 0 \\
$\chi 2$ & \multicolumn{3}{c}{0,77} \\
\hline LPS & 60 & 20 & 20 \\
Não injetado & 42,9 & 42,9 & 14,2 \\
Injetado & \multicolumn{2}{c}{0,41} & \\
$\chi 2$ &
\end{tabular}


Quanto às enzimas analisadas no soro sanguíneo (Tab. 6), não houve mudanças substanciais com relação aos fatores estudados, indicando que a injúria causada e/ou o tempo de intervalo entre a inoculação e a coleta das amostras não foram suficientes para alterar as quantidades delas.

Nos escores de comportamentos, observou-se que os animais inoculados com LPS tiveram um comportamento de acordo com o esperado, para uma resposta inflamatória aguda, com surtos de vômito, diarreia e prostração, a partir da primeira medição, feita aos 30 minutos $\left(\chi^{2}<0,05\right)$. Berg et al. (2004), trabalhando com camundongos, verificaram que os animais inoculados com LPS tiveram uma clara redução no comportamento social. No presente trabalho, nenhum nível de $\beta$ glucanos conseguiu reverter estes sintomas, pois, analisando-se os níveis de $\beta$-glucanos, não houve diferença significativa $(\mathrm{P}>0,05)$, assim como não houve interação entre $\beta$-glucanos *LPS.
Com base nos custos dos ingredientes e do produto comercial utilizado, no mês de agosto de 2011, a suplementação do produto na dieta dos leitões elevaria em $2,9 \%$ o custo desta. $\mathrm{O}$ cálculo da relação custo/benefício torna-se difícil de ser feito, pois não houve efeito no desempenho dos animais. Por outro lado, o benefício pode ser imaginado tal como um segurado se beneficia de seu seguro em caso de ocorrência de determinado sinistro. Em situações de desafio imunológico, caso os leitões tenham uma menor reação inflamatória, haverá menor risco de perda de desempenho em função de perda de apetite e febre, entre outros sintomas (Klasing e Leshchinsky, 1999). Nesse caso, é correto pensar que aqueles recebendo $\beta$-glucanos poderão apresentar menor reação inflamatória, tendo menores perdas de desempenho.

Tabela 6. Análise da medida de aspartato amino transferase (AST), alanina amino transferase (ALT) e fosfatase alcalina (FAL) no soro sanguíneo em U/L - 180 minutos após inoculação LPS

\begin{tabular}{|c|c|c|c|c|c|c|}
\hline & \multicolumn{2}{|c|}{ AST } & \multicolumn{2}{|c|}{ ALT } & \multicolumn{2}{|c|}{ FAL } \\
\hline \multirow[b]{2}{*}{$\begin{array}{c}\beta-\text { glucanos } \\
(\mathrm{g} / \mathrm{T})\end{array}$} & \multicolumn{6}{|c|}{ LPS } \\
\hline & $\begin{array}{c}\text { Não } \\
\text { injetado }\end{array}$ & Injetado & $\begin{array}{c}\text { Não } \\
\text { injetado }\end{array}$ & Injetado & $\begin{array}{c}\text { Não } \\
\text { injetado }\end{array}$ & Injetado \\
\hline 0 & 55,3 & 55,3 & 42,3 & 44,3 & 328,3 & 339,0 \\
\hline 35 & 24,0 & 60,7 & 41,0 & 46,0 & 268,7 & 413,3 \\
\hline 70 & 32,7 & 67,7 & 45,0 & 39,0 & 339,0 & 457,3 \\
\hline 140 & 104,0 & 38,0 & 43,0 & 39,3 & 312,0 & 278,3 \\
\hline 280 & 48,3 & 65,7 & 37,3 & 41,7 & 314,3 & 384,0 \\
\hline Média & 52,9 & 57,5 & 41,7 & 42,1 & $312,5 a$ & $374,4 \mathrm{~b}$ \\
\hline \multicolumn{7}{|l|}{ Probabilidade } \\
\hline$\beta$-glucanos & \multicolumn{2}{|c|}{0,767} & \multicolumn{2}{|c|}{0,977} & \multicolumn{2}{|c|}{0,270} \\
\hline LPS & \multicolumn{2}{|c|}{0,745} & \multicolumn{2}{|c|}{0,941} & \multicolumn{2}{|c|}{0,038} \\
\hline $\begin{array}{l}\text { B-glucanos } \\
\text { *LPS }\end{array}$ & \multicolumn{2}{|c|}{0,163} & \multicolumn{2}{|c|}{0,908} & \multicolumn{2}{|c|}{0,269} \\
\hline $\mathrm{CV} \%$ & \multicolumn{2}{|c|}{69,3} & \multicolumn{2}{|c|}{28,9} & \multicolumn{2}{|c|}{22,3} \\
\hline
\end{tabular}

\section{CONCLUSÃO}

O uso de $\beta$-glucanos por 14 dias na dieta de leitões recém-desmamados mostrou ter efeito anti-inflamatório, evitando maior elevação de temperatura retal dos leitões em reações agudas causadas por injeção de LPS. Para reverter o desafio imunológico utilizado, o nível de $280 \mathrm{~g} / \mathrm{T}$ de $\beta$-glucanos mostrou-se o mais recomendado. As demais respostas fisiológicas avaliadas nesse experimento, bem como o desempenho, não foram afetadas pelo uso de $\beta$-glucanos. 


\section{REFERÊNCIAS}

AMATI, L.; LEOGRANDE, D.; PASSERI, M.E. et al. $\beta$-glucans: Old molecules with newly discovered immunological activities. Drug Des Rev-On, v.3, p.251-258, 2005.

BERG, B.M.; GODBOUT, J.P.; KELLEY, K.W. et al. Alpha-tocopherol attenuates lipopolysaccharideinduced sickness behavior in mice. Brain Behav. Immun., v.18,149-157, 2004.

CHENG, Y.-H.; LEE, D.-N.; WEN, C.-M. et al. Effects of $\beta$-glucan supplementation on lymphocyte proliferation, macrophage chemotaxis and specific immune responses in broilers. Asian - Austr. J. Anim. Sci., v.17, p.1145-1149, 2004.

DRITZ, S.S.; SHI, J.T.L.; KIELIAN, R.D. et al. Influence of dietary B-glucan on growth performance, nonspecific immunity, and resistance to Streptococcus suis injection in weaning pigs. J. Anim. Scie., v.73, p.3341-3350, 1995.

EICHER, S.D.; MCKEE, C.A.; CARROLL, J.A.; PAJOR, E.A. Supplemental vitamin C and yeast cell wall $B$-glucan as growth enhancers in newborn pigs and as immunomodulators after an endotoxin challenge after weaning. J. Anim. Sci., v.84, p.23522360, 2006.

EXPORTAÇÕES de Carne Suína por Destinos: Comparativo Jan/Dez2011 x Jan/Dez2010. São Paulo: Associação Brasileira da Indústria Produtora e Exportadora de Carne Suína, 2011. Disponível em: <www.abipecs.org.br>. Acessado em: 15 ago. 2011.

HAHN ,T.-W; LOHAKARE, J.D.; LEE, S.L. et al. Effects of supplementation of $\beta$ - glucans on growth performance, nutrient digestibility, and immunity in weanling pigs. J. Anim. Sci., v.84, p.1422-1428, 2006.

KLASING, C.K.; LESHCHINSKY, T.V. Interactions between nutrition and immunity. nutrition and immunology: principles and practice. [s.p.]: Humana Press, 1999. p.363-371,

LI, J.; XING, J.; LI, D. et al. Effects of beta-glucan extracted from Saccharomyces cerevisiae on humoral and cellular immunity in weaned piglets. Arch. Anim. Nutr., v.59, p.303-12, 2005.

MAO, X.F.; PIAO, X.S.; LAI, C.H. et al. Effects of Bglucan obtained from the Chinese herb Astragalus membranaceus and lipopolysaccharide challenge on performance, immunological, adrenal, and somatotropic responses of weanling pigs. J. Anim. Sci., v.83, p.2775-2782, 2005.
MENDES, C.B.S.; FONTES, D.O.; GUEDES, R.M.C. et al. Suplementação de betaglucano a dietas de leitões de 21 a 60 dias de idade. Arq. Bras. Med. Vet. Zootec., v.62, p.696-705, 2010.

ROBERTSEN, B.; RORSTAD, G.; ENGSTAD, R. et al. Enhancement of non-specific disease resistance in Atlantic salmon, Salmo salar L., by a glucan from Saccharomyces verevisiae cell walls. J. Fish Dis., v.13, p.391-400, 1990.

ROITT, I.M.; DELVES, P.J. Roitt: fundamentos de imunologia. 10.ed. Rio de Janeiro: Guanabara Koogan, 2004. 489p.

ROSTAGNO, H.S. Tabelas brasileiras para aves $e$ suínos: composição de alimentos e exigências nutricionais. 2.ed., Viçosa: UFV, 2005. 186p.

STATISTICAL analysis system for Windows. Cary: SAS Institute, 2001

SCHOENHERR, W.D.; POLLMANN, D.S.; COALSON, J.A. Titration of MacroGard - $S$ on growth performance of nursery pigs. J. Anim. Sci., 1994. v.72 (suppl 2), 413. Abstr. $\mathrm{N}^{0} 57$.

SELJELID, R.L.; RASMUSSEN, T.; LARM, O. et al. The protective effect of $B 1-3 \mathrm{D}$ - glucan - derivatized plastic beads against Escherichia coli infection in mice. Scan. J. Immunol., v.25, p.55-60, 1987.

SILVA, T.C.P.; MOTA, S.B.; ALMEIDA, M.M.C. et al. Efeito do tamoxifeno no perfil das proteínas plasmáticas em condição de diabetes mellitus tipo 1 . Acta Cir. Bras., v.20 suppl.1, p.86-93, 2005.

SIGMA-ALDRICH Safety Data Sheet according to Regulation (EC) No. 1907/2006 Product Name of Lipopolysaccharides, from Escherichia coli 055: B5. 2009. Disponível em: <www.sigma-aldrich.com>. Acesso em 10 jan. 2009.

WRIGHT, K.J.; BALAJI, R.; HILL, C.M. et al. Integrated adrenal, somatotropic, and immune responses of growing pigs to treatment with lipopolysaccharide. J. Anim. Sci., v.78, p.1892-1899, 2000.

ZHONG, W.; YUMING, G.; JIANMIN, Y. et al. Effect of dietary beta-1,3/1,6-glucan supplementation on growth performance, immune response and plasma prostaglandin, growth hormone and ghrelin in weanling piglets. Australas. J. Anim. Sci., may, 2008. 